\title{
Alianzas Familiares y Reproducción Social de la Elite Mercantil de Cádiz, 1700-1812
}

\section{PALOMA FERNANDEZ PEREZ Universidad de Barcelona}

Ya desde el siglo XVI las ventajas de la situación geoestratégica de Cádiz otorgaron a esta ciudad un atractivo especial para la comunidad de comerciantes de toda Europa que deseaban participar en el comercio colonial con la América espanola. Tal concentración de recursos físicos y humanos incrementó el papel institucional, económico y social de la ciudad como centro peninsular del Imperio mercantil español, aún después de los decretos liberalizadores de la segunda mitad del siglo XVIII (1).

La historiografía se ha ocupado de resaltar el impacto económico y político del auge y caída de Cádiz como centro económico del Imperio español. Poca atención se ha prestado, sin embargo, al impacto social en los protagonistas directos de tales acontecimientos: las familias de comerciantes al por mayor residentes en Cádiz. Como grupo social estas familias necesariamente debieron ser influídas y a' la vez debieron influir en el desarrollo y en la crisis económica que marcaron la transición a un nuevo tipo de organización económica y social en España. Hechos cruciales como la transición de España desde una economía mercantil con una sociedad patriarcal dominada por corporaciones a una economía basada en la agricultura comercializada y en la incipiente industrialización, ambas lideradas por la llamada "nueva" clase burguesa del siglo XIX defensora del individualismo y el liberalismo, se han analizado tradicionalmente como hechos aislados. Al siglo XVIII con su organización económica y social lo suplantarían una nueva clase y actividades productivas en el XIX. Reputados historiadores como Jaume Vicens Vives,' o Pierre Vilar, han conectado, con matices, comercio colonial, desarrollo agrícola, e incipiente industrialización en el caso catalán, pero no existe ningun estudio que trate de analizar globalmente qué interrelación existió, a lo largo del

(1) Antonio GARCIA-BAQUER GONZALEZ, Cádiz y el Atlántico, $1717-1778$ (El comercio colonial español bajo el monopolio gaditano). 2 vols. Cádiz: ,Diputación Provincial de Cádiz, 1988. Idem, Comercio colonial y guerras revolucionarias. La decadencia económica de Cádiz a raíz de la emancipación americana. Sevilla: Escuela de Estudios HispanoAmericanos/C.S.I.C., 1972. Idem, Comencio y burguesía mercantil en el Cádiz de la Carrera de Indias. Cádiz: Diputación Provincial de Cádiz, 1991.

DOI: http://dx.doi.org/10.25267/Trocadero.1995.i6.03 
siglo XVIII, entre actividad económica y reproducción social de los protagonistas máximos del comercio colonial en la península: los comerciantes de Cádiz (2).

El presente trabajo, basado en la tesis de doctorado de la autora, resume parcialmente un estudio amplio realizado sobre unos mil individuos, hombres y mujeres, miembros de las familias de la élite mercantil de Cádiz (3). A través de la reconstrucción prosopográfica de varias generaciones de familias, y en relación a la evolución económica y política del Imperio español entre 1700 y 1812 , se analizan e interpretan elementos clave de la la interrelación entre vida privada y coyuntura económica, en un período histórico decisivo en la transición de España desde estructuras propias de Antiguo Régimen a las del siglo XIX liberal y burgués.

\section{FUENTES PARA EL ESTUDIO DE LA FAMIIIA}

A diferencia de la Italia renacentista o la Inglaterra de la edad moderna, para los cuales existe una gran abundancia de diarios y autobiografias, en los territorios del mundo hispano hay una gran laguna en cuanto a la conservación de fuentes directas que nos transmitan una versión personal del pasado familiar, por lo menos hasta el siglo XIX. En este sentido el caso del Cádiz dieciochesco es modélico, por la ausencia de diarios personales y porque en una investigación profunda de las veinticinco notarias públicas de que disponía la ciudad en el siglo XVIII, apenas se han encontrado más de veinte inventarios que permitan al historiador obtener testimonios directos detallados y extensos de la vida y mentalidad de la época. Para el siglo XVII contamos con las excepcionales memorias del comerciante afincado en Cádiz de origen saboyano Raimundo de Lantery (4). Para el siglo XVIII, sin embargo, las fuentes más ricas en cantidad y calidad de información biográfica son los protocolos notariales y los documentos de tipo eclesiástico procedentes de parroquias y arzobispađo.

Entre los primeros destacan, además de los escasos inventarios de riqueza, las disposiciones testamentarias. Testamentos, poderes para testar individuales y recíprocos, testamentos en virtud de poder y particiones de bienes contienen información biográfica del testador y su familia consanguínea más directa, con frecuencia datos sobre capital y dote aportados al matrimonio, y más raramente declaraciones personales sobre la visión que de la propia vida, familia y negocios tenía el testador (5). Debido a la alta concentración demográfica, que llegó hasta los 70.000 habitantes en pleno siglo, y a las numerosas notarías de la ciudad, la localización de los hombres y mujeres ligados al comercio al por mayor con América del presente trabajo hubo de apoyarse en dos utilísimos catálogos publicados. Uno, relativo a los comerciantes matriculados en el Consulado de Comercio

(2) Manuel BUSTOS, en distintos artículos y libros, ha analizado exhaustivamente casos particulares de comerciantes radicados en Cádiz, como los Colarte.

(3) Paloma Fernández Pérez, Family and Marriage Around Colonial Trade: Cádiz, 1700-1812 Tesis doctoral inédita (University of California at Berkeley, 1994).

(4) Manuel BUSTOS RODRIGUEZ, ed., Un comerciante saboyano en el Cádiz de Carlos Il (Las memorias de Raimundo de Lantery, 1673-1700). Cádiz: Caja de Ahorros de Cádiz, 1983

(5) Un estudio detallado de las disposiciones testamentarias de Cádiz, desde el punto de vista de las mentalidades religiosas de amplios sectores de la población, en María José de la Pascua Sánchez, Vivir la muerte en el Cádiz del setecientos (1675-1801). Cádiz: Fundación Municipal de Cultura y Ayuntamiento de Cádiz, 1990. 
de Cádiz, y otro sobre la totalidad de individuos que hicieron disposiciones testamentarias en Cádiz entre 1740 y 1775 (6). Contrastando ambos catálogos se llegaron a localizar disposiciones testamentarias de unos mil individuos hombres y mujeres pertenecientes a las familias del comercio con America establecidas en Cadiz, representativos de la diversidad de orígenes geográficos y socioeconómicos del total de familias comerciantes de Cádiz. Con estas ayudas previas de la catalogación archivística se recogió la muestra base de la investigación de este estudio, que incluye unos doscientos treinta legajos para los períodos $1740-1750$ y 1760 1770 , veintiocho para la época entre 1750 y. 1760 , dieciocho para los años 1770 a 1775 , setenta legajos para los años 1776-1799, y treinta y un legajos para los años entre 1810 y 1812 . Inicialmente se buscó a los comerciantes varones cuyos nombres aparecían listados como comerciantes españoles (peninsulares y americanos) y extranjeros en los listados nominales publicados por J. Ruiz Rivera y A. GarcíaBaquero. En segundo lugar, y tras una reconstrucción prosopográfica de las disposiciones testamentarias halladas para estos individuos, se inició la búsqueda de las mujeres del grupo, básicamente esposas, hijas y madres de comerciantes (matriculados o no) relacionados con el comercio al por mayor con América. El análisis de la mentalidad de las mujeres desde una perspectiva histórica, sobre todo la de las mujeres pertenecientes a sectores de la élite social, ha de tomar en cuenta, sin embargo, la frecuente presencia de un familiar varón, junto a la mujer, en el momento de dictar la disposición testamentaria al notario. En varios casos estudiados para Cádiz se ha podido recoger el testimonio de mujeres que acudían al notario para anular testamentos otorgados contra la voluntad de la mujer, que fueron firmados bajo presión de un marido o un familiar consanguíneo (7). Los lazos matrimoniales y familiares afectaban los lazos mercantiles en todos aquellos territorios gobernados por las leyes de Castilla, tanto en la península como en América.

(6) Julian B. RUIZ RIVERA, El Consulado de Cádiz. Matrícula de comerciantes, 1730-1823. Cádiz: Diputación Provincial de Cádiz, 1988. Los métodos y datos de matriculados de Ruiz Rivera han sido criticados y revisados en A. GARCIA-BAQUERO, Comercio y burguesia mercantil..., 86-101, y en Antonia HEREDIA HERRERA, Sevilla y los bombres del comercio (1700-1800). Sevilla: Editoriales Andaluzas Unidas, 1989, 34-35. Las disposiciones testamentarias catalogadas y publicadas están en Manuel RAVINA e Isabel CEBALLOS, Indice de las Disposiciones Testamentarias de Cadiz, 1740-1775. Madrid: Dirección de Archivos Estatales, 1991. Existen en base de datos computerizada listados nominales no publicados desde 1775 hasta 1812, gentilmente facilitados a la autora por el director del Archivo Histórico Provincial de Cádiz, Manuel Ravina. Para los primeros cuarenta años del siglo se están catalogando aún las disposiciones.

(7) La experiencia más detallada de tales presiones se halla narrada por Luisa de Torres, hermana del comerciante Miguel de Torres, cuñada del comerciante Manuel del Corro y Hoz, y esposa del comerciante de origen irlandés Pedro Strange. Strange, en asociación con su compañero en el comercio y sobrino Guillermo Molone, hizo que Luisa de Torres firmara un documento que ella ni siquiera pudo leer. En el documento, que era un testamento, Luisa había firmado su renuncia a todo derecho que pudiera tener a reclamar su parte legítima de bienes en caso' de muerte de su, esposo, lo que forzaría así la disolución de la compañia comercial Strange-Molone. Luisa lo descubrió, y buscó aliados influyentes en la ciudad que testificaran que estaba sana y cuerda, y a continuación consiguió un notario que redactó la anulación del valor del testamento firmado contra su voluntad. Archivo Histórico Provincial de Cadiz (A.H.P.C.) Notaria 3, protocolo 774: folio 457-463. El documento que hubo de firmar bajo presión está en A.H.P.C. Notaría 25, procolo 5747: folio 607-613. Luisa otorgó otro testamento en A.H.P.C. Notaría 11, protocolo 2179: folio 308-312. 
La muerte de un comerciante, en este contexto legislativo, supuso en más de una ocasión la urgencia femenina de liquidar el negocio del marido difunto para poder disponer de efectivo con que afrontar la subsistencia de la familia en la viudedad. Pero el comercio, tanto en Europa como en América en la época colonial, no constituía una actividad económica aislada. Particularmente el comercio colonial precisaba de la creación y mantenimiento de una compleja red internacional de productores, agentes, comisionistas, y comerciantes correspondientes. Desde el punto de vista de una compañía mercantil, la liquidación de negocios debía ser un proceso realizado lenta y cuidadosamente, para procurar obtener buenos precios de la venta de mercancías. Ventas realizadas con la urgencia requerida por viudas precisadas de efectivo podían suponer la quiebra de los socios supervivientes de la compañía, y de los agentes que invertían tiempo y esfuerzo en el negocio de la compañía. Es por este motivo que los comerciantes varones solian estar presentes y vigilantes cuando las mujeres de la familia otorgaban una disposición testamentaria, lo que evidentemente coartaba la libertad de expresar sin presiones valores y estrategias propias del sector femenino del grupo. A pesar de este problema, se han utilizado para el presente estudio doscientas setenta y siete disposiciones testamentarias de otras tantas mujeres, ciento cuarenta y ocho de las cuales otorgaron sus documentos ante notario sin presencia de un varón familiar consanguíneo directo.

Dentro de los protocolos notariales, dos tipos documentales constituyen igualmente piezas básicas en la reconstrucción de las estrategias de reproducción social de un grupo: las cartas o recibos dotales, y las declaraciones de capital. Ambos tipos de documentos recogen en general el valor total de lo aportado por la mujer y el hombre al matrimonio, y lo que el varón se comprometía a entregar como bien propio de la esposa en forma de arras -que en general equivalía a un diez por ciento del valor total de bienes del novio-. Con este tipo de datos, a lo largo de una centuria, se pueden reconstruír los cambios en sistemas de alianzas matrimoniales, observando los cambios en la cuantía del valor de bienes dados por la familia de la esposa en forma de dote y la relación de estos cambios del valor de la dote con los cambios experimentados en la cuantía del capital aportado al matrimonio por el varón. Para el presente estudio se han utilizado más de 300 documentos que recogen datos sobre dotes y capitales de las familias de comerciantes de Cádiz, entre 1700 y 1812.

El otro grupo de fuentes útiles para reconstruír los valores y estrategias familiares de la sociedad española, peninsular y americana, son documentos de origen eclesiástico. En el caso de Cádiz los documentos de origen inquisitorial no son de gran ayuda, ya que buena parte de la documentación de la Inquisición para esta zona de Andalucía, conservada en Sevilla, se destruyó en los siglos XIX y XX. La parroquia de Santa Cruz y desde 1787 sus parroquias auxiliares (de San Lorenzo, San Antonio, Nuestra Señora del Rosario y San José Extramuros), y el archivo histórico diocesano de Cádiz constituyen más bien los archivos clave de referencia. Por una parte, los índices y registros parroquiales de bautismos, matrimonios (públicos, y secretos con dispensa de amonestaciones), y defunciones proporcionan el material necesario para reconstruír sistemas de reproducción social de un grupo determinado, a partir de la reconstrucción de: las alianzas espirituales establecidas en el padrinazgo bautismal, la edad de acceso al matrimonio, la frecuencia de segundos y terceros matrimonios, la fecundidad legítima e ilegítima, y las alianzas interraciales e interconfesionales entre católicos y no católicos residentes en la ciudad. Tales datos, a menudo elaborados por los 
demografos, han sido investigados para este trabajo con un interés más bien antropológico e histórico, tratando de analizar los valores y mentalidad que regían la reproducción social del grupo estudiado y la relación entre este sistema cambiante de valores y la evolución del comercio colonial con América.

Por otro lado, las visitas eclesiásticas de la diócesis, los expedientes matrimoniales, las requisitorias de Indias y las demandas de esponsales y de divorcios conservadas en el archivo histórico diocesano de Cádiz constituyen las otras fuentes de origen eclesiástico ricas en testimonios sobre la vida familiar del Cádiz de la época, especialmente en lo referido a transgresiones del orden pacífico querido por la Iglesia católica. Las visitas, redactadas por sacerdotes delegados del obispo, permiten observar la pervivencia de la costumbre pre-tridentina del matrimonio consuetudinario (reconocido por la comunidad pero sin estar consagrado por la Iglesia), y los problemas de bigamia que sobre todo entre clases humildes existían derivados de la dificultad de averiguar los datos de soltería de individuos inmigrantes procedentes de países no catolicos o de areas lejanas o en guerra con España (8). Los expedientes permiten obtener con precisión la edad de los contrayentes, y el dato interesante de los viajes realizados por los novios con anterioridad al matrimonio. Las requisitorias de Indias reflejan el impacto que la migración masiva de hombres, solteros pero también casados (que podían marchar sin sus esposas a América cuando éstas les otorgaban permiso expreso por escrito), tuvo en la quiebra de la estructura familiar de la población de Cádiz. Mujeres abandonadas con hijos que mantener habían de hacer frente, con la mendicidad a menudo, a la marcha hacia América de aquellos hombres que invertían prácticamente todos sus pequeños y medianos recursos económicos en mercancías y en el viaje transatlántico, dejando poco o nada a la familia que dejaban atrás en la península (9). Las demandas de esponsales (por promesas incumplidas de matrimonio) y de divorcio constituyen, como las requisitorias, documentos clave en España y en América de estudio de la conflictividad social y familiar en particular antes del siglo XIX (10).

(8) Archivo Diocesano de Cádiz. Sección I. Secretaría. Visitas pastorales. Años 1711-1823: Legajos 506, 507, 508, 509, 510 (I), 510 (II) y 511 (I); Manuscritos 1234 y 1235.

(9) Archivo Diocesano de Cádiz. Sección IV. Varios. Años 1750-1825: Legajos 1855, 1856, 1857. Ias familias de mayor poder económico y status social ý político no aparecen apenas en las requisitorias, y en general sus miembros dejaron asignaciones regulares de dinero para sus mujeres e hijos cuando viajaron' fuera de Cádiz, designando a un comerciante conocido o a la propia esposa como administradores de bienes previamente definidos para poder sustentar a la familia en su ausencia. Tales designaciones, con la ocasión de un viaje fuera de la ciudad, se hallan genieralmente en un tipo de documento denominado "poder para testar". Ia situación de la mayoría de comerciantes de Cádiz, sin embargo, no era de gran poder económico, como se indica más adelante en la sección sobre las diferencias internas del grupo mercantil en Cádiz.

(10) Archivo Diocesano de Cádiz. Sección IV. Varios. Añós 1699-1814: Legajos 678, 707, 708, $631,1049,1056,935,305,626,733,1054,627,1055,1067,1603$. Para la ciudad de México, expedientes matrimoniales y demandas de esponsales han constituído la base documental clave del estudio de Patricia SEED: To Love, Honor and Obey in colonial Mexico. Conflicts over Marriage Cboice, 1574-1821. Stanford: Stanford University Press, 1988. Para Lima, las demandas de 'divorcio y de nulidad son la fuente básica para el estudio de la conflictividad familiar en los estudios de Bernard LAVALLE: "Divorcio y nulidad de matrimonio en Lima (1650-1700) (La desavenencia conyugal como indicador social), Revista Andina, 4:2 (1986): pp. 427-464. Y también el estudio para Lima de Alberto FLORES GALINDO y Magdalena CHOCANO, "Las cargas del sacramento", Revista Andina, 2:2 (1984): pp. 403-434. 
Tanto requisitorias como demandas de esponsales y de divorcios fueron mayoritariamente iniciadas ante la curia eclesiástica de Cádiz por mujeres, y por mujeres pertenecientes a sectores sociales humildes y trabajadores relacionados sobre todo con el servicio doméstico, el abastecimiento al por menor de alimentos en tiendas y puestos callejeros y la elaboración artesanal y venta de productos textiles. La escasa presencia en este tipo de documentos, transmisores de conflictividad familiar, de sectores de la élite de la nobleza, la burocracia, y el comercio, plantea cuestionarse el por qué aparentemente los conflictos privados aireados en público sólo se desarrollaban entre sectores humildes, y qué tipo de presiones existían dentro de las élites para conseguir el silencio y la paz interior familiar. El análisis de los comportamientos familiares de 558 hombres y 294 mujeres, relacionados directamente con el comercio colonial con América, a través de los protocolos notariales y documentos eclesiásticos de archivos gaditanos, ha permitido averiguar que la estrecha conexión entre el comercio y la formación de la familia existente en Cádiz precisó de orden, paz, y discreción con el objetivo de no perjudicar los intereses socioeconómicos de las familias de la élite mercantil.

\section{LOS COMERCIANTES DE LA “CARRERA DE INDIAS" EN CADIZ}

Como grupo social, los comerciantes al por mayor de Cádiz representaron en el siglo XVIII aproximadamente un 15\% del total de la población de la ciudad, entre 200 y 500 individuos como promedio a lo largo del siglo (11). Un 50\% de ellos habían nacido en territorio español peninsular o americano, y el restante $50 \%$ en otros países europeos (sobre todo Francia, Irlanda, e Italia). Entre los nacidos en territorios españoles, y según el padrón municipal de 1773 , un $40 \%$ procedía de villas, pueblos y ciudades de la actual provincia de Cádiz, y el resto de otras áreas de Castilla, con un peso importante de los comerciantes de origen vasco-navarro, y una presencia reducida de comerciantes procedentes de áreas del Levante mediterráneo y América. Destaca de la lectura de estas cifras la fuerte

(11) Las cifras numéricas concretas varían según los autores, en función de la nomenclatura que cada historiador acepta de padrones, censos municipales, y otras fuentes como la matrícula de comerciantes, pero el porcentaje es aproximadamente 15\%. Manuel BUSTOS, Historia de Cádiz (Los siglos decisivos). Madrid: Silex, 1990, pp. 54-56. A. GARCIA-BAQUERO, Comercio y burguesía mercantil..., pp. $74-75$ y 84. Segun el Almanak Mercantil o Guía de Comerciantes, que proporcionaba información sobre todas las plazas de comercio españolas, peninsulares y americanas, entre 1795 y 1808 , el número de comerciantes al por mayor avecindados en Cádiz varió de 650 a 780 entre 1795 y 1800; tras la epidemia de fiebre amarilla, sólo había 308 en 1803 , subiendo a $\mathbf{4 7 0}$ justo antes del asedio francés de la ciudad, en 1808. Para estos datos, y los relativos a número de comerciantes en distintas plazas peninsulares y americanas cuyos nombres listaba el Almanak, Paloma FERNANDEZ PEREZ, Prensa económica del siglo XVIII: El Almanak Mercantil o guía de comerciantes (1795-1808). Tesis de licenciatura inédita (Universidad de Barcelona, 1987). Para el dato sobre el número de comerciantes en las plazas americanas de comercio de Veracruz, Guadalajara, Lima y Buenos Aires, según el Almanak, Paloma Fernández Pérez, "El Almanak Mercantil o Guía de Comerciantes (1795-1808) como fuente para la historia económica de España y América", en Historias 22. Revista de la Dirección de Estudios Histónicos del Instituto Nacional de Antropologia e Historia de México, (1989), pp. 189-192. 
inmigración interprovincial, e internacional a Cádiz, el cosmopolitismo de la comunidad mercantil en Cádiz, y la coexistencia tolerante de diferentes' culturas y religiones en los tratos mercantiles.

Las diferencias dentro del grupo de comerciantes al por mayor de Cádiz no se limitaron al origen geográfico. En el interior del grupo había diferencias basadas en el género y el origen socioeconómico. Prácticamente todos los comerciantes al por mayor implicados en el negocio colonial eran hombres, pero hubo excepciones y numerosas mujeres se dedicaron al negocio mercantil con América. La mayoría de ellas eran mujeres casadas o viudas de comerciantes que administraban el negocio familiar en caso de fallecimiento del cónyuge, y toda vez que el esposo se hallaba ausente de viaje en América o por el resto de España y Europa.También hubo, sin embargo, solteras en edad adulta que aprendiendo con rapidez técnicas básicas de compra-venta practicadas en una ciudad tan mercantil como Cádiz invirtieron pequeños y medianos capitales en mercancías que entregaban a agentes a comisión que tramitaban la venta en América (12). Además, y considerando a un sector mercantil diferente, aunque relacionado con el comercio al por mayor, el de los mercaderes de vara, en 1771 de un total de 396 mercaderes existentes en la ciudad, 112 eran mujeres (13). Como indicara ya en su Curia Philipica el tratadista Juan de Hevía Bolaños, las mujeres no podían legalmente ejercer cargos públicos, pero el oficio de mercader no podía considerarse cargo público al no resultar de una elección previa y por lo tanto legalmente las mujeres podían ser mercaderes (14). La práctica femenina de la mercadería y el comercio al por mayor en Cádiz fue un hecho, y en la administración de sus negocios utilizaron a menudo sistemas de valores diferentes a los utilizados por comerciantes varones. En función de su género ejercieron con frecuencia la solidaridad con otras mujeres y prefirieron, en general, la disgregación de patrimonio para lograr el bienestar familiar antes que la concentración de riqueza preferida por los comerciantes varones (15).

En cuanto a las diferencias internas debido a la situaçión socioeconómica, Didier Ozanam ha establecido categorías respecto a la comunidad de comerciantes franceses, indicando una jerarquía de poder económico que estaría encabezada por comerciantes asociados en casas de comercio de gran capital común, y comerciantes al por mayor de gran poder negociador. Tras ellos se situarían estrechamente ligados aquellos comerciantes que se iniciaban en el comercio con América y que trataban de asociarse a conocidas casas o comerciantes por lazos profesionales y/o matrimoniales. Utilizando las estimaciones del Catastro de Ensenada y de la Unica Contribución, que reflejan de forma aproximativa niveles de beneficios comerciales obtenidos por comerciantes españoles y extranjeros en la

(12) Paloma FERNANDEZ PEREZ, Family and Marriage Around Colonial Trade. Cádiz, 1700 1812. Tesis doctoral inédita (University of California at Berkeley, 1994): pp. 15-16.

(13) La lista original de mercaderes de vara de Cádiz de 1771 ha sido publicada en A. GARCIABAQUERO, Comercio y burguesía mercantil..., pp. 115-120.

(14) La edición manejada no: es la original, sino una posterior, de 1797. Juan de HEVIA BOLAÑOS, Curia Pbilipica. Madrid: Oficina de Ramón Ruiz, 1797, II:1, 1: p. 265.

(15) Más detalle de las diferentes prácticas y mentalidades de la élite mercantil de Cádiz en función del género, en Paloma FERNANDEZ PEREZ, "Mujeres y burguesía en el Cádiz del siglo XVIII", comunicación presentada en el Congreso Intermacional La bunguesía española en la edad moderna. Universidad Complutensé de Madrid, 1991. (En prensa). 
segunda mitad de siglo, Antonio García-Baquero ha elaborado otra clasificación de niveles de riqueza, demostrando cómo en 1762 sólo un $25 \%$ del total de comerciantes españoles tenían utilidades comerciales estimadas por encima de los 1.000 pesos, cantidad que se considera promedio de las utilidades estimadas del grupo. Un $50 \%$ de comerciantes españoles, si se consideran fiables las cifras del Catastro, tenían utilidades anuales por debajo de los 500 pesos, mientras que del grupo de comerciantes no españoles sólo un escaso $10 \%$ tenía utilidades por debajo de los 1.000 pesos. Los extranjeros controlaban, desde estas cifras, el grueso de los beneficios obtenidos del comercio colonial con América, pues un 30\% de comerciantes no españoles obtenía más de 5.000 pesos al año de beneficios de sus actividades mercantiles (16).

La diversidad de orígenes, culturas, mentalidad y niveles socioeconómicos induce a concluir que las estrategias de alianza y reproducción social del grupo de comerciantes fueron igualmente diversas en función de los antedichos factores. Un análisis de las costumbres y prácticas de herencia de las familias de comerciantes de origen francés, irlandés, vasco-navarro, catalán, y castellano prueba que efectivamente hubo diferentes estrategias adoptadas en Cádiz por la elite mercantil. Comerciantes procedentes del sur de Francia y Cataluña tendieron a concentrar su patrimonio (especialmente el establecido en sus tierras de origen) en un solo heredero, de preferencia el varón primogénito, mientras que costumbres y prácticas de reparto igualitario entre varones y hembras eran comunes entre las familias comerciantes de origen castellano. Por otro lado, la mayoría de comerciantes nacidos fuera de Andalucía, o pertenecientes a familias procedentes de áreas no andaluzas, tendieron a establecer alianzas matrimoniales con familias de similar origen y cultura, especialmente aquellas familias con mayor poder económico y status social, de lo cual son un buen ejemplo las estrategias de endogamia geográfica y profesional de los comerciantes naturalizados de origen irlandés Lorenzo Ley y Nicolas Jennet (17).

Pero de la misma forma que existió una diversidad de comportamientos en función de la diversidad interna del grupo de comerciantes avecindados en Cádiz, puede observarse la presencia de pautas homogéneas en ciertos aspectos de las estrategias matrimoniales y de reproducción social, homogeneidad que debe interpretarse en gran medida por el impacto de la evolución del comercio colonial en las estructuras familiares del grupo social más ligado a tal actividad economica. Entre dichas pautas comunes a todo el grupo destaca la estrecha conexión que existió entre: auge del comercio colonial e incremento paulatino del papel de la mujer en la vida pública y en la administracion de la economía y negocio familiares, por un lado, y entre evolución del comercio con América y formación de la familia a través del matrimonio y nacimiento de hijos. Ambos tipos de interrelación son los analizados a continuación.

(16) A. GARCIA-BAQUERO, Comercio y burguesia mercantil..., pp. 67-101. Idem, Cádiz y el Atläntico..., p. 487. Didier Ozanam, "La colonie francaise de Cadix au XVIIIe siecle d'aprés un document inédit (1777)", Mélanges de la Casa de Velázquez 6 (1968): pp. 259-348.

(17) Paloma FERNANDEZ PEREZ, Family and Marriage Around Colonial Trade. Cádiz, 1700-1812. Tesis doctoral inédita. (University of California at Berkeley, 1994), 235-238 (alianzas establecidas por Ley y Jennet) y 265-274 (costumbres de herencia según origen geográfico-cultural). 


\section{FORMACION DE LA FAMILIA Y COMERCIO COLONIAL EN CADIZ}

El antropólogo Jack Goody ha señalado de forma precisa que el control familiar sobre las alianzas familiares y la transmisión de patrimonio y status es tanto mayor cuanta mayor propiedad posea la familia (18). Desde este punto de vista, la libertad e independencia de los individuos pertenecientes a niveles socioeconómicos superiores se ven fuertemente limitadas por el interés e interferencia de los restantes miembros del grupo familiar, entendido éste no como una unidad nuclear sino como una unidad extensa que ligaba a parientes consanguineos y no consanguíneos (19). Además, en el caso de los territorios gobernados por legislación castellana, como Cádiz, la costumbre de transmitir la riqueza familiar a través de la mujer, en forma de dote y de parte igualitaria de herencia paterna y materna (legítima) requirió en general una estrecha supervisión de la mujer.

Viajeros extranjeros que visitaron la ciudad de Cádiz a principios del siglo XVIII destacaban la sumisión, discreción, y recato de las mujeres de la élite, encerradas'en el claustro o en el lugar para ellas reservado en el hogar: el estrado (20). Sin embargo, en los últimos veinte años del siglo los mismos viajeros extranjeros resaltaron que esas mismas mujeres habían cambiado el recato y el encierro por la presencia pública y la participación en tertulias de caracter literario y político frecuentadas por varones (21). Sermones pronunciados en los púlpitos de las iglesias de Cádiz, y publicados para lectura de la población, como los del influyente prebendado Cayetano María Huarte, condenaban a fin de siglo el abandono por la mujer de la esfera tradicionalmente reservada para ella: el cuidado del esposo y de los hijos (22).

El cambio producido en el rol de la mujer respecto a su familia detectado por los viajeros no era resultado de una serie de impresiones subjetivas. Con cada marcha de la flota, una o dos veces al año en dirección a América, cientos de navegantes aceptaron el desafío de abandonar la ciudad para enfrentarse a la aventura de enriquecerse rápidamente al otro lado del océano. En promedio, esos hombres regresaron a Cádiz tras un año y medio o dos, pero muchos encontraron

(18) Jack GOODY, The development of the family and marriage in Europe. Cambridge: Cambridge University Press, 1983.

(19) Una introducción útil a estos conceptos en James CASEY, The History of the Family. Oxford: Blackwell, 1989.

(20) Así lo expresó en 1705 el misionario francés Jean-Baptiste Labat, en texto recogido en J. GARCIA MERCADAL, Viajes de extranjeros por España y Portugal. Madarid: Aguilar, 1962, vol. III (siglo XVIII), pp. 128-129.

(21) Tal era la imagen que recibió el visitante francés J.F. Peyron, recogida en J. GARCIA MERCADAL, Viajes de extranjeros..., pp. 799-800 y 879.

(22) Cayetano María de HUARTE Y BRIVIESCA, Sermón Moral que en la Solemne Profesión de Sor Maria Juana de la Asuncion, en el siglo doña Juana Caters, en el Convento de RR. MM. Descalzas de la ciudad de Cádiz el siete de diciembre de 1787 predico el sr. d.. Cadiz: Imprenta de Juan Ximénez Carreño, 1788: pp. xiv-xv. Idem, Sermón que en 19 de febrero de 1777 Miercoles despues de la primera Dominica de Cuaresma, predico a la Real Audiencia de Contratacion a Indias, en la Iglesia de RR. PP. Carmelitas Descalzos el Sr.. Doctor en Sagrada Teologia y Prebendado de la Santa Iglesia Catedral de Cadiz. Cádiz: Don Manuel Espinosa de los Monteros, Impresor Real de Marina, 1777, pp. xiii-xiv. Ambos conservados en la Biblioteca de Temas Gaditanos de Cádiz. 
dificultades en el viaje o en la estadía, y muchos incluso fallecieron o decidieron adoptar una nueva vida en América tuvieran o no mujer e hijos esperándoles en Cádiz. Así, entre 1750 y 1796 por lo menos 203 mujeres legalmente solicitaron al obispo de Cádiz la iniciación de los procedimientos necesarios para hacer regresar de América a prometidos o maridos que ya se habían ausentado de sus obligaciones familiares por más de tres y cuatro años, utilizando la fuerza si fuera preciso (23). Las ausencias de varones debidas a la migración profesional temporal crearon dificultades a las mujeres que debían sobrevivir a menudo de préstamos hasta la llegada del esposo, pero además tales ausencias contribuyeron a alterar el rol de la mujer como individuo subordinado de la unidad familiar.

Un análisis de los padrones municipales de 1713 y 1773 revela el considerable peso de la mujer como cabeza de familia ante la migración mercantil masculina en Cádiz. En 1713 las mujeres cabeza de familia representaban aproximadamente un $26 \%$ del total de cabezas de familia registrados para la ciudad, y en 1773 representaban alrededor de un $14 \%$, porcentajes inferiores pero equiparables a los altos porcentajes de mujeres cabeza de familia hallados en censos de ciudades latinoamericanas como Sao Paulo o México (24). El padrón de 1713 indica, para las mujeres cabeza de familia casadas con marido ausente, dónde se hallaba el marido: de un total de 313 mujeres casadas cabezas de familia, 231 tenían al marido "ausente en las Indias", un 73\%. En el padrón de 1773, de las 111 mujeres casadas cabezas de familia con marido ausente, 45 tenían al marido ausente en América (25).

Estas cifras se refieren a la población de Cádiz en general, pero analizando información procedente de los protocolos notariales del archivo histórico provincial gaditano se ha obtenido un dato que permite comprobar cómo la marcha a América afectó a las mujeres de las familias de comerciantes al por mayor de Cádiz: de una muestra de 221 comerciantes que fueron a América por lo menos una vez en viaje de negocios entre 1700 y 1812,106 eran solteros en el momento

(23) Archivo Diocesano de Cádiz. Requisitorias de Indias. Legajos 1855, 1856 y 1857.

(24) En el Sao Paulo de mediados del siglo XVIII y en la brasileña Vila Rica de principios del siglo XIX había más mujeres cabezas de familia que hombres en los censos, debido a las migraciones a las minas y a zonas de expansión económica. Elizabeth Ann KUZNESOF, Housebold economy and urban development. Sao Paulo 1765 to 1836. Boulder and London: Westview Press,1986. Donad RAMOS, "Marriage and the Family in Colonial Vila Rica", Hispanic American Historical Review 55, 2 (1975): pp. 200-225. En la ciudad de México en el censo de 1811 un tercio de todas las casas registradas eran encabezadas por una mujer, en el contexto de una fuerte migración masculina al campo, según Silvia M. ARROM, "Marriage patterns in Mexico City, 1811", Joumal of Family History 3, 4 (1978): pp. 376-391. Elizabeth Kuznesof ha indicado que la importancia numérica de mujeres cabeza de familia podria ser un rasgo que caracterizara más a Latinoamérica que a Europa, en "Household, Family, and Community Studies, 1976-1986: A Bibliographical Essay", Latin American Population History Newsletter 14 (1988): pp. 9-11. Los diversos trabajos de Caroline Brettell para Portugal, y el presente trabajo sobre el Cádiz dieciochesco más bien sugieren que tal rasgo sería común a todas aquellas áreas en las que por necesidades económicas hubiera una fuerte migración masculina.

(25) Archivo Municipal de Cádiz. Padrones. Padrón de 1713 (Legajo 1003) y Padrón de 1773 (Legajos 1006 y 1007). Elaboración de cifras propia, en P. FERNANDEZ PEREZ, Family and Marriage Around Colonial Trade..., p. 96. 
de partir, 8 viudos y 107 casados (uno de los casados voluntariamente separado de su mujer). De los 115 comerciantes que se fueron dejando atrás una esposa y/o hijos que mantener en su ausencia, 22 decidieron viajar a América por primera vez el mismo año de su boda, 91 de ellos viajaron a partir de cumplirse un año de la boda, y sólo dos comerciantes viajaron a América antes de su boda. Por otro lado, 24 comerciantes decidieron partir el mismo año en que sus esposas quedaron embarazadas por primera vez o hubieron dado a luz el primer hijo de la unión y 30 viajaron coincidiendo con un embarazo de sus esposas o un parto reciente que incrementaba las bocas que necesitaban alimento (26).

Estos números evidencian la clara conexión entre la creación de una familia a través del matrimonio y el nacimiento del primer hijo, y la voluntad de emprender la aventura mercantil con América para sostener a la familia. Lo cual, además, sugiere que los viajes a América, en estos casos, se iniciaban con la necesidad de incrementar los recursos económicos necesarios para sostener una familia y que, por tanto, al partir de viaje no se dispondría de gran riqueza como para sostener durante mucho tiempo a la familia recién creada que se dejaba atrás (27).

La interrelación estrecha existente entre la decision de iniciar la "carrera de Indias" y la reproducción de las familias de comerciantes a través de alianzas matrimoniales no se mantuvo sin cambios a lo largo del siglo. En profunda relación con la evolución del volumen de comercio colonial realizado en Cádiz, el momento de contraer matrimonio y el momento de entrar plenamente en el comercio colonial a través de la matrícula en el Consulado de Comercio estuvieron más próximos antes de 1740-1750 que a partir de esos años. Tales variaciones se observan en los siguientes cuadros:

\section{CUADRO 1 \\ Diferencias en las edades de acceso al matrimonio en Cádiz entre 130 comerciantes y sus esposas, 1700-1812}

Fecha Matrimonio

\begin{tabular}{cccc}
$\begin{array}{c}\text { Diferencia edad } \\
\text { esposos, en años }\end{array}$ & Entre 1700 y 1750 & Entre 1751 y 1812 & Entre 1700 y 1812 \\
\hline $0-5$ & 22 enlaces $(47.8 \%)$ & 24 enlaces $(28.2 \%)$ & 46 enlaces \\
$6-10$ & $9(19 \%)$ & $19(22.3 \%)$ & 28 \\
$11-15$ & $6(13 \%)$ & $19(22.3 \%)$ & 25 \\
$16-20$ & $6(13 \%)$ & $11(12.9 \%)$ & 17 \\
$21-25$ & $2(4.3 \%)$ & $10(11.7 \%)$ & 12 \\
$26-30$ & $1(2.1 \%)$ & $1(1.1 \%)$ & 2 \\
& $46(100 \%)$ & $84(100 \%)$ & 130
\end{tabular}

(26) Protocolos notariales del A.H.P.C. Información elaborada en P. FERNANDEZ PEREZ, Family and Marriage Around Colonial Trade..., p. 91, cuadro 2.2.

(27) Algunos comerciantes dejaron financiación suficiente para mantener a sus familias' en 'su ausencia, como lo prueban los casos detallados en P. FERNANDEZ PEREZ, Family and Marriage Around Colonial Trade..., pp. 91-94. 
Fuente: Archivo Diocesano de Cádiz. Sección 2. Vicaría General. Expedientes Matrimoniales. Legajos 129, 134, 154, 159, 163, 185, 189, 211, 212, 220, 221, 225 , $226,237,238,247,250,254,265,269,272,275,286,287,288,289,293,296,298$, $299,301,302,304,306,307,309,310,312,313,316,320,323,327,337,338,341$, $342,344,346,347,348,354,357,358,360,361,362,363,364,365$, 367II, 368, $372,373,374,375,377,380,381,382,385,391$, 395I, 395II, 395III, 396bis, 398, $401,406,409,410,411,418,429$, 430, 456, 470, 472bis, 500, 502, 568, 583, 633.

\section{CUADRO 2 \\ Edad de acceso al primer matrimonio entre las familias de comerciantes de Cádiz}

\begin{tabular}{lcccccc} 
Año primer & \multicolumn{3}{c}{ Hombres } & \multicolumn{3}{c}{ Mujeres } \\
\cline { 2 - 7 } matrimonio & $\begin{array}{c}\text { Total } \\
\text { individuos }\end{array}$ & $\begin{array}{c}\text { Edad } \\
\text { (promedio) }\end{array}$ & $\begin{array}{c}\text { Edad } \\
\text { (mediana) }\end{array}$ & $\begin{array}{c}\text { Total } \\
\text { individuos }\end{array}$ & $\begin{array}{c}\text { Edad } \\
\text { (promedio) }\end{array}$ & $\begin{array}{c}\text { Edad } \\
\text { mediana }\end{array}$ \\
\hline $1700-1750$ & 74 & 27.11 & 26 & 33 & 21 & 20 \\
$1751-1800$ & 101 & 31.84 & 32 & 47 & 21.63 & 21
\end{tabular}

Fuente: Protocolos notariales del Archivo Histórico Provincial de Cádiz, elaborados en P. Fernández Pérez, Family and Marriage Around Colonial Trade, apéndice 1, pp. 426-506.

\section{CUADRO 3}

Relación entre las fechas del primer matrimonio y el año de matrícula en el Consulado de Cádiz, 1700-1811

\begin{tabular}{ccccc}
$\mathbf{A}$ & $\mathbf{B}$ & $\mathbf{C}$ & $\mathbf{D}$ & $\mathbf{E}$ \\
\hline $1700-1759$ & 159 & $106(66.6 \%)$ & $43(27 \%)$ & $10(6.2 \%)$ \\
$1760-1811$ & 96 & $21(21.8 \%)$ & $69(71.8 \%)$ & $6(6.2 \%)$ \\
$1700-1811$ & 255 & $127(49.8 \%)$ & $112(43.9 \%)$ & $16(6.2 \%)$
\end{tabular}

Fuente: Protocolos notariales del Archivo Histórico Provincial de Cádiz, elaborados en P. Fernández Pérez, Family and Marriage Around Colonial Trade..., apéndice 1 , pp. 426-506.

A: Año de celebración del primer matrimonio de comerciantes matriculados. Se consideran matrimonios celebrados en Cádiz, Sanlúcar de Barrameda, Puerto de Santa María, Chiclana, Isla de León y Medina Sidonia (zona de influencia cercana a Cádiz).

B: Número de matrimonios, de comerciantes matriculados, celebrados entre los años indicados.

C: Número de comerciantes matriculados cuyo primer matrimonio se celebró antes de matricularse en el Consulado, en un plazo de un año o más antes de la matrícula (\%sobre B).

D: Número de comerciantes matriculados en el Consulado cuyo primer matrimonio se celebró después de matricularse en el Consulado, en un plazo de por lo menos un ano después de la matrícula (\% sobre B).

E: Número de comerciantes matriculados cuyo primer matrimonio se celebró el mismo año en que se matricularon en el Consulado de Comercio (\% sobre B). 
La lectura del cuadro 1, en primer lugar, indica que del total de 103 matrimonios recogidos por la muestra la gran mayoria de enlaces se celebraron con novios de edad más avanzada que la edad de las novias, especialmente en la segunda mitad de siglo, y sólo en diez matrimonios la novia tenía una edad superior a la del novio. Según las cifras del cuadro, las parejas que se casaron en la primera mitad del siglo en general tenían entre sí una diferencia de edades de menos de cinco años en $47 \%$ de casos de la muestra, y la diferencia de edades de más de once años sólo afectaba a un 35\% del total de la muestra para la primera mitad de la centuria. En la segunda mitad de siglo, en la época del despegue decisivo de las exportaciones e importaciones del puerto de Cádiz, el porcentaje de parejas cuyas edades diferían hasta cinco años era del $28 \%$ mientras que el de parejas con diferencia de edad superior a once años se había incrementado sensiblemente al $48 \%$.

En otras palabras, con el incremento del volumen del comercio colonial, los comerciantes varones se casaban cada vez más tarde, probablemente después de haber consolidado sus fortunas y posición social gracias a la carrera de Indias, mientras que en la primera mitad de siglo considerada de "despegue". del comercio los comerciantes habrían preferido casarse antes como medio de aliarse con otros comerciantes y obtener medios para iniciar los negocios a través de la dote de la esposa. Tal impresión parece confirmada por el cuadro 2 en el que se aprecia claramente cómo en la segunda mitad de siglo la edad promedio de acceso al matrimonio por primera vez de comerciantes varones se retrasa casi cinco años con respecto a la edad promedio de la primera mitad de siglo; sin embargo, la edad promedio de acceso al matrimonio de las mujeres de la muestra apenas sufre variación a lo largo del siglo.

La explicación de tal diferencia, de nuevo, remite a las diferentes posibilidades ofrecidas por la carrera de Indias a lo largo del siglo. Desde fines del siglo XVII y primeros años del XVIII los comerciantes que traficaban con América solían ser por un lado extranjeros (italianos, flamencos, franceses), con pocas raíces en Andalucia, necesitados muchos de alianzas con familias andaluzas para poder entrar, legalmente, en el comercio americano, y por otro lado andaluces, castellanos, norteños e individuos del Levante mediterráneo con poco capital propio a los que una buena dote de una familia notable local podía proporcionar medios para iniciar la aventura de América (28). A partir del despegue definitivo del tráfico con América en Cádiz, a partir de la década de 1740, los comerciantes tenían mayores oportunidades que antes de crear grandes fortunas en poco tiempo, y por tanto menor necesidad de establecer alianzas matrimoniales y obtener dotes.

Esta plausible hipótesis, que explica el retraso en la edad de acceso al matrimonio de los comerciantes conforme avanzaba el siglo XVIII, se refuerza con un estudio del cuadro 3. De un total de 255 comerciantes matriculados casados en Cádiz y su área más próxima, casi un 67\% de los casados antes de 1760 se casa-

(28) Un tratamiento extenso de la evolución de la dote en Cádiz, para la población en general y para los comerciantes matriculados en el Consulado en particular, en Paloma FERNANDEZ PEREZ, "Familia y transmisión de propiedad en el siglo. XVIII. La evolución de la dote en Cádiz, 1740-1810", comunicación presentada a las I Jomadas de Demografía Histórica de Andalucía. Universidad de Cádiz, Cádiz, 1992 (En prensa). 
ron antes de matricularse en el Consulado de Comercio de Cádiz, mientras que casi un $72 \%$ de los casados a partir de 1760 y hasta 1811 lo hicieron después de un año o más de haberse matriculado en el Consulado.

El matrimonio en la segunda mitad de siglo se retrasaba, adelantándose más bien la participación formal en el comercio americano dada la mayor actividad y riqueza derivada del trafico colonial en esta época. Ejemplos de carreras individuales confirman estos datos. El vizcaíno Juan Antonio de Uriarte Urbanco declaró en su expediente matrimonial de 1798 que él había dejado su valle natal de Somorrostro en 1785 para venir a Cádiz cuando tenía 16 años de edad. Desde 1785 hasta el año de su boda en Cádiz con María de los Angeles Comba Rodríguez, en 1798, viajó a América tres veces por motivos de sus negocios comerciales (29). De forma similar, el comerciante nacido en Cádiz de origen francés Pedro Felipe Venel Reybeaud se casó con la hija del comerciante irlandés naturalizado español Nicolas Jennet en 1768, cuando tenía 43 años de edad, después de haber realizado previamente varios viajes a Nueva España (30). El vasco José Antonio de la Gacha Sagastiverri, quien llegó a Cádiz cuando tenía 14 años de edad, viajó a Buenos Aires con 18 años de edad, y permaneció en esa ciudad durante catorce años, hasta su retorno a Cádiz en 1763, y cuatro años más tarde decidió casarse con Manuela Sánchez de Osorio, quien tenía en 1767 diecinueve años de edad (31).

El retraso de la edad masculina de acceso al matrimonio a lo largo del siglo, entre los comerciantes al por mayor, se ha observado igualmente para el caso de otras ciudades mercantiles del siglo XVIII como Buenos Aires, y Burdeos, y la hipótesis que liga tal retraso con el menor interés en obtener dotes gracias a las mayores posibilidades de enriquecerse con la actividad profesional se ha utilizado de forma convincente para el Brasil colonial (32).

\section{ACUMULACION DE CAPITAI Y REPRODUCCION FAMIIIAR}

La hipótesis que conecta el retraso masculino en el acceso al matrimonio, y el declinar en el atractivo de la dote, con el crecimiento económico de la segunda mitad del siglo XVIII presupone en primer lugar que efectivamente los comerciantes al por mayor de Cádiz obtuvieron mayores beneficios derivados de su actividad mercantil en la segunda mitad de la centuria que antes, y que en conse-

(29) Archivo Diocesano de Cádiz. Sección 2. Vicaría General. Expedientes Matrimoniales. Legajo 568.

(30) Archivo Diocesano de Cádiz. Sección 2. Vicaría General. Expedientes Matrimoniales. Legajo 401.

(31) Archivo Diocesano de Cádiz. Sección 2. Vicaría General. Expedientes Matrimoniales. Legajo 395. Otros ejemplos, Ignacio Rodríguez Báez y María Dolores Lasqueti (Archivo Histórico Provincial de Cádiz, Notaría 25, protocolo 5760: folio 518-521) e Isidro Rodríguez Báez y María Rosa García del Canto (A.H.P.C., Notaría 25, protocolo 5760: fol. 514-517).

(32) Susan MIGDEN SOCOLOW, "Marriage, Birth, and Inheritance: The Merchants of EighteenthCentury Buenos Aires", Hispanic American Historical Review 60:3 (1980): p. 390 . Paul Butel, "Comportements familiaux dans le négoce bordelais au XVIIIe siécle", Annales du Midi 88: 127 (1976): pp. 139-152. Muriel Nazzari, "Parents and Daughters: Change in the Practice of Dowry in Sao Paulo (1600-1770)", Hispanic American Historical Review 70:4 (1990): pp. 639-665. Idem, Disappearance of the dowry: women, families and social cbange in Sao Paulo, Brazil (1600-1900). Stanford: Stanford University Press, 1991. 
cuencia hubo un desinterés creciente en el rol promotor de la dote, en segundo lugar. La veracidad de ambas supposiciones es lo que se analiza a continuación, para poder interpretar la interrelación entre crecimiento económico y crisis de una de las estrategias clave de reproducción social de la familia antes del siglo XIX: la dote.

Se ha demostrado que efectivamente hubo un aumento del tráfico de importaciones y exportaciones del puerto de Cádiz, pero las evidencias utilizadas para demostrar que de forma particular los comerciantes de Cádiz acumularon riqueza a partir de la década de 1740 se han basado, en la historiografía sobre el tema, en el análisis de sólo veintiún inventarios de riqueza pertenecientes a otros tantos comerciantes avecindados en Cádiz (33). El siguiente cuadro presenta una visión más amplia del enriquecimiento de los comerciantes de Cádiz a lo largo del siglo, a partir de 228 capitales que aportaron en el momento del matrimonio otros tantos comerciantes.

\begin{tabular}{|c|c|c|}
\hline \multicolumn{3}{|c|}{$\begin{array}{l}\text { CUADRO } 4 \\
\text { Valor monetario (pesos de } 128 / 4 \text { ) de } 228 \text { capitales } \\
\text { aportados al matrimonio por comerciantes de Cádiz, 1700-1780 }\end{array}$} \\
\hline Pesos 128/4 & $\begin{array}{l}\text { 1700-1740 } \\
\text { Número Capitales } \\
\quad(\% \text { total })\end{array}$ & $\begin{array}{l}1741-1780 \\
\text { Número Capitales } \\
\quad(\% \text { total })\end{array}$ \\
\hline $\begin{array}{l}0-500 \\
501-1.000 \\
1.001-5.000 \\
5.001-10.000 \\
+10.000\end{array}$ & $\begin{array}{c}43(55.8 \%) \\
5(6.4 \%) \\
7(9 \%) \\
4(5.1 \%) \\
18(23.3 \%) \\
\text { Total: } 77(100 \%)\end{array}$ & $\begin{array}{c}75(49.6 \%) \\
2(1.3 \%) \\
17(11.2 \%) \\
11(7.2 \%) \\
46(30.4 \%) \\
\text { Total: } 151(100 \%)\end{array}$ \\
\hline
\end{tabular}

Fuente: Disposiciones testamentarias, recibos de dote y declaraciones de capital del Archivo Histórico Provincial de Cádiz, elaborados en P. Fernández Pérez, Family and Marriage Around Colonial Trade..., apéndice 3, pp. 533-571.

Observando la tabla, se detectan dos claras tendencias en la evolución de capitales llevados al matrimonio por los comerciantes de Cádiz a lo largo del siglo: el incremento obvio de "ricos" capitales por encima de los 1.000 pesos, de $37 \%$ a $49 \%$ de la muestra; y por otro lado, el notable descenso de los capitales "pobres" por debajo de los 1.000 pesos, del 62\% al 50\% de la muestra recogida en el cuadro. Según el análisis efectuado sobre el volumen del tráfico mercantil del puerto de Cádiz de A. García-Baquero, hubo un crecimiento sostenido que se

(33) La localización y análisis de estos inventarios se hallan en A. GARCIA-BAQUERO, Cádiz y el Atlântico..., pp. 525-526. Una crítica parcial de las fuentes utilizadas por A. GARCIABAQUERO se halla en P. Fernández Pérez, Family and Marriage Around Colonial Trade... pp. 22-23. 
habría iniciado alrededor de 1709 , y que se habría transformado en un decisivo despegue de exportaciones e importaciones desde 1748 a 1788 (34). Tomando en cuenta este dato, y los valores de capitales de la tabla, parece claro que los efectos de la prosperidad derivada de la evolución del comercio colonial tuvieron un impacto visible en el incremento del valor de las fortunas que los novios comerciantes llevaron a su matrimonio en la segunda mitad de siglo. Tal incremento permitía potencialmente una mayor mobilidad e independencia social y económica que antes. Los comerciantes, que se casaban en edades más adultas que antes, podían retrasar su decisión de casarse y formar alianzas con familias apropiadas cuyas dotes ya no eran tan necesarias como podian serlo a principios de siglo. Viajaban a América y se registraban en la matrícula del Consulado de Comercio mucho antes que se casaban. De este modo se crearon condiciones favorables para la progresiva independencia de los varones de las presiones de la familia patriarcal corporativa ya que, y siguiendo el argumento del antropólogo Jack Goody, al tener menor incentivo la propiedad transmitida por la esposa disminuía paralelamente el poder e interés de la familia de la mujer en controlar la nueva unidad familiar. Tal independencia económica, a finales de siglo y principios del siglo XIX, vino a apoyar la mayor independencia en la elección que la segunda y tercera generación de familias de comerciantes debían tomar acerca de qué carrera profesional seguir, siguiendo con frecuencia la carrera militar, administrativa, o eclesiástica, o la propiedad de tierras desamortizadas explotadas de forma comercial (35).

El declinar del interés en la dote, en el contexto de crecimiento del comercio colonial de la segunda mitad de siglo, fue un proceso lento pero definitivamente un hecho, como lo demuestra el análisis del cuadro inferior, que recoge el valor monetario de 302 dotes aportadas por las familias de comerciantes de Cádiz, entre 1700 y 1780 .

\section{CUADRO 5}

Valor monetario de 302 Dotes aportadas por las familias de comerciantes de Cádiz, entre 1700 y 1780

\begin{tabular}{lcc} 
Pesos 128/4 & $\begin{array}{c}\mathbf{1 7 0 0 - 1 7 4 0} \\
\text { Número de Dotes } \\
\text { (\% total) }\end{array}$ & $\begin{array}{c}\mathbf{1 7 4 1 - 1 7 8 0} \\
\text { Número de Dotes } \\
\text { (\% total) }\end{array}$ \\
\hline $0-500$ & $50(53.1 \%)$ & $112(53.8 \%)$ \\
$501-1.000$ & $3(3.1 \%)$ & $4(1.9 \%)$ \\
$1.001-5.000$ & $26(27.6 \%)$ & $40(19.2 \%)$ \\
$5.001-10.000$ & $6(6.3 \%)$ & $18(8.7 \%)$ \\
+10.000 & $9(9.5 \%)$ & $34(16.3 \%)$ \\
& Total: $94(100 \%)$ & Total: $208(100 \%)$
\end{tabular}

(34) A. GARCIA-BAQUERO, Cádiz y el Atlántico..., p. 541. Idem, Decadencia comercial y guerras revolucionarias..., p. 35.

(35) Mayor análisis del destino profesional de segundas y terceras generaciones, en P. FERNANDEZ PEREZ, Family and Marriage Around Colonial Trade..., 341-351. 
Fuente: Disposiciones testamentarias, recibos de dote y contratos matrimoniales del Archivo Histórico Provincial de Cádiz, elaborados en P. Fernández Pérez, Family and Marriage Around Colonial Trade..., pp. 533-571.

Comparando este cuadro relativo a dotes con el cuadro referido a capitales, se advierte que mientras los capitales inferiores a 1.000 pesos, aportados al matrimonio por los comerciantes, significativamente decrecieron despues de 1740 como probable resultado de la bonanza económica, las dotes inferiores a 1.000 pesos permanecieron estables tras esos años de despegue mercantil, representando el $56 \%$ y el $55 \%$ de la muestra de dotes para $1700-1740$ y $1741-1780$ respectivamente. La prosperidad económica pareció beneficiar a los novios más que a las novias. Este hecho se confirma por el ligero cambio en el valor de las dotes superiores a 1.000 pesos. Todas las dotes entregadas superiores a 1.000 pesos representaron el $43 \%$ de la muestra en las cuatro primeras décadas del siglo, y el $44 \%$ en los cuarenta años siguientes, un incremento insignificante si se tienen en cuenta dos circunstancias. En primer lugar, que considerando las enormes fortunas que se crearon a partir de 1740 y hasta la década de 1780 (reflejadas en el aumento del valor del capital aportado por los varones comerciantes), sería de esperar que los comerciantes entregaran a sus hijas como dote elementos de un valor más rico que en los primeros años de siglo como sucedía en el caso de los capitales llevados por los varones, y ello no fue claramente así. Y en segundo lugar, en la segunda mitad de siglo mientras en general las dotes de mayor valor no experimentaron un incremento espectacular y las dotes entre 1.000 y 5.000 pesos disminuyeron proporcionalmente, los novios estaban llevando fortunas más considerables al matirmonio que las novias. En conclusión, el crecimiento económico, y la espectacular creación de fortunas que tuvieron lugar entre 1740-1780 contribuyeron a incrementar la fortuna material de los miembros masculinos de la élite mercantil en Cádiz, pero tuvieron un điferente impacto en función del género, al mantenerse estable el valor de las dotes, en comparación con el valor de los capitales. El declinar de la dote en Cádiz, pues, no tuvo una correspondencia con una época de crisis económica, sino más bien con un cambio en las estrategias y valores de las familias de comerciantes. Si a principios de siglo lograr una novia con una buena dote era el medio fundamental de establecer alianzas y de introducirse en la carrera de Indias, en la segunda mitad de siglo la gran mobilidad económica y social proporcionada por el negocio con América hizo que fuera más bien un novio prometedor el medio fundamental de enriquecimiento y ascenso social. La dote, inevitablemente, empezó a perder el papel de estrategia familiar de alianza y reproducción social ante el ascenso económico individual. La transición a la familia nuclear burguesa conocida en la Europa occidental a partir del siglo XIX así halló sus inicios en el Cádiz dieciochesco, y su análisis puede servir de modelo interpretativo para comprender el declinar de la dote en el mundo hispano. 